cases possibly even as a textbook. And, finally, the diverse array of scientists, policy makers, and advocates involved in the global warming debate will find this book useful as a status report on the science at the turn of the millennium.

The book is so well written that there is little in it that one can take issue with. I was amazed at how much complex and detailed scientific information the author was able to convey without the use of a single illustration or equation and with very few acronyms. The tutorial on weather and climate processes contains a few minor flaws, but few readers other than pedantic professors will be bothered by them. (Ironically, the explanation of the atmosphere's compressibility contains the same error that thwarted Sir Lewis Richardson in his historic attempt to forecast the weather based on the governing equations.) A bit more troubling is the author's treatment of the role of global warming in increasing the frequency of occurrence of extreme weather events. Although it is clearly not his intent, his dramatic portrayal of the deluges and blizzards of the 1990s in chapter 11 could give some readers the impression that many of these events would not have occurred had it not been for the unprecedented (global) warmth of that decade. One could also question whether the link between global warming and extreme weather events is as well established or as widely accepted in the scientific community as portrayed in the concluding section of chapter 11.

The reader interested in Stevens's own opinions gleaned from his experience as a science writer can find hints of them in his choice of protagonists, and in the passion with which he writes about various topics. But it is very much to his credit that he has treated the arguments and the scientists on both sides of the global warming debate with fairness and respect. Some readers are bound to think he is partial to the "activist/environmentalist" wing of the scientific community, while others will think he has given the arguments of the "contrarians" more space than they deserve. As the author soberly concludes in the book's final sentence, "The experiment is running and time will tell."-John M. Wallace.

John M. Wallace is a professor at the University of Washington in Seattle.

\title{
In Memoxiam
}

\author{
Robed A. Browne \\ Alleat $\mathscr{L}$. Foust \\ 1923-2000 \\ $1917-2000$ \\ - Nancy E. Cobb- Ball \\ 19.5.9-2000 \\ John T. Goodwin \\ 1946-1999 \\ Alent Eliassen \\ - Masalo Murakami \\ 1915-2000 \\ 1946-2000
}

